\title{
Vision Grand: A Village in the City
}

\section{Uli / Gerald D. Hines Urban Design Graduate Student Competition}

\section{CRAIG Minus}

The Urban land Institute holds the Gerald D. Hines Urban Design Competition for graduate students every year. In a very short period of time, the interdisciplinary teams of students are given a project theme, a city, and a site to which they have to respond with a complete design proposal, including pro-formas, financing, and implementation strategies. Craig Minus writes about his team's submittal, awarded an Honorable Mention in 2006.

In 2006, for the first time, a Cal Poly team entered the Urban Land Institute's Gerald D. Hines Urban Design Competition for graduate students. Participating teams have to be interdisciplinary, and they have only 10 days to present their proposals from the day the ULI releases the site, the theme and the problem. Eighty one teams from across the U.S. \& Canada participated in last year's competition, and the jurors selected four "Final Teams" and seven "Honorable Mentions." Final teams went into a second phase when they were given some more time to further develop their projects for the final round. The Cal Poly team was selected as one of the "Honorable Mentions."

The ULI urban design competition was in St. Louis, Miss. and comprised a 100-acre parcel spanning the proposed Chouteau Greenway and acting as a bridge between the North and South campuses of Saint Louis University (SLU). The area would also serve as a point of entry into the city's planned greenway system and the multimodal transportation spine that parallels the greenway. The competition asked participating teams to act as the master developer for the entire parcel and to consider private, public, institutional and nonprofits as development and equity partners. The teams were asked to include a mix of uses as well as to incorporate the proposed future greenway and open space plans into their design ideas.

\section{The Cal Poly Project}

Vision Grand: a Village in the City, the Cal Poly team's proposal, includes residential, mixed-use, commercial and office developments, and the design allows for the incorporation of the emerging biotechnology industry. Where the Chouteau Greenway intersects with the Grand Boulevard Bridge, a tight-knit, fine-grain village builds cohesion between the two Saint Louis University campuses, provides a base for bio-tech companies and incubators, and establishes a medium-density, pedestrian oriented neighborhood with a unique and eclectic character.

The project proposes the Grand Boulevard Bridge as an icon providing a strong identity and sense of place in the area. The design generates a harmonious interface between the Chouteau Greenway and the areas surrounding the Grand Boulevard, strengthening the connection between the North and South campuses of SLU. The new street, pedestrian and bicycle systems are well integrated and provide for a balance of mobility options. Bicycle routes to and from Chouteau Greenway and Park encourage active recreation and healthy transportation to/from work and school. Convenient routes are established connecting activity centers inside and outside the project area. A shuttle service along Grand Boulevard between the two campuses is proposed, and the Metro station will ignite and support transit-oriented development.
Craig Minus was in Cal Poly's MCRP class of 2005. He is currently project manager for real estate development, The Towbes Group, Inc. 
Buildings will utilize green design principles, such as appropriate materials for facades and southfacing windows with overhangs to create passive solar heating and cooling. They will be designed to coexist with nature and pose minimal harm to the environment by implementing sustainable design principles. Materials from demolished buildings will be reused in concrete for parking areas, foundations and bicycle and pedestrian paths. Gray water from the area and the bio-tech industry will be reused and recycled for irrigation and act as a water feature flowing out into the park. Bioswales will collect storm water runoff from the surrounding street grid. The open space system will integrate the new development to the Chouteau Greenway, provide cohesion between both sides of the site, and allow for various recreational choices for employees, students, and residents alike. Pocket parks will be a special feature of the open space system creating more intimate spaces.

The relationship between public and private realms plays an important role in the project, and the two domains are clearly defined and support each other. Active street frontages provide for a pedestrianfriendly environment and for safe sidewalks, and the pedestrian experience is enhanced by a wide variety of mixed uses and complementary activities. The urban design strategy creates a split from denser and higher buildings to open space and the greenway, and the staggered building heights and street layout respect view sheds.

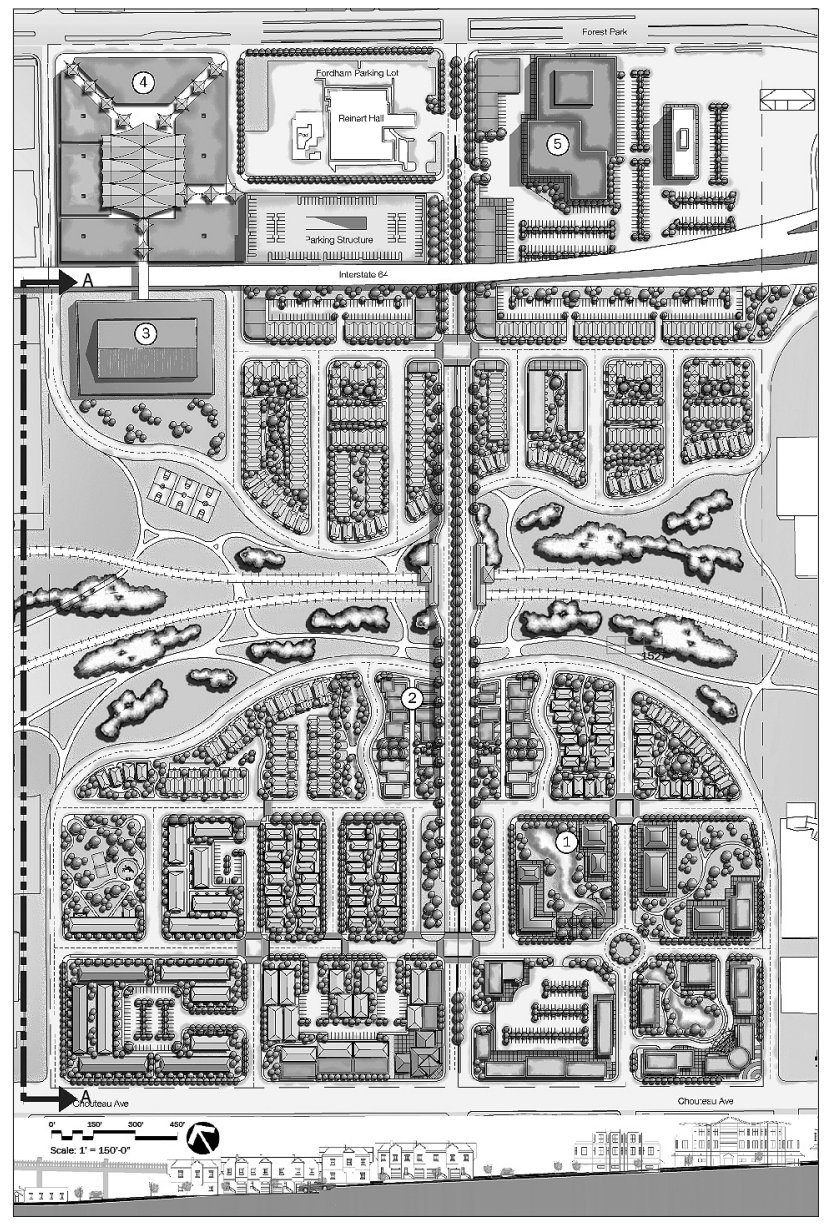

Several of the images that composed the team's submittal to the ULl's Gregory D. Hines Urban Design Competition, 2006. The project occupies a 100-acre parcel that spans the Chouteau Greenway and bridges the North and South campuses of Saint Louis University.

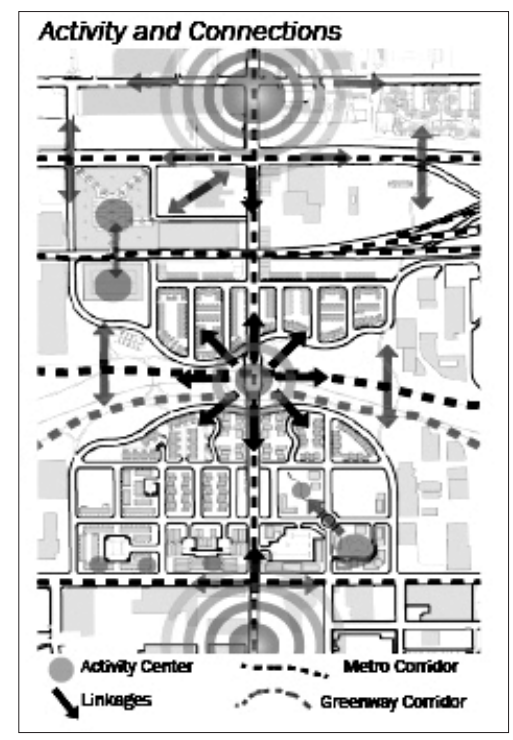


The project's financial strategy capitalizes on the emerging Bio-tech industry as a catalyst for improvement, and a tax increment is used to finance 9 percent of the total costs. New Market Tax Credit for Bio-tech and Federal Historic Preservation Tax Credit for armory building are transferred to private syndicators at $\$ .085$ per dollar. The Land Clearance for Redevelopment Authority supports a portion of pre-development costs, construction of road and public utilities costs. Environment Protection Agency P2 Grant funds the construction of the bioswales for fostering environmental protection. Traditional financing is also used with tax-free bonds at the rate of 4.75 percent, and developers bear the remaining project costs with private equity.

\section{The Experience}

For the participating graduate students, the learning opportunity crammed into just 10 short days provided a valuable experience on both an academic and practical level. The lessons and applications offered from the competition project was equivalent to the knowledge gained from a quarter-long class. The five graduates students, who in many cases did not know each other before the competition, came together to combine talents and produce a quality deliverable. Throughout the 10 days, the interdisciplinary team quickly grew together to work as industry practitioners would. This experience helped simulate the professional environment and prepare the students for life in the workforce. The ULI/ Gerald D. Hines competition also allowed the students to further emphasize Cal Poly's "learn by doing" motto.
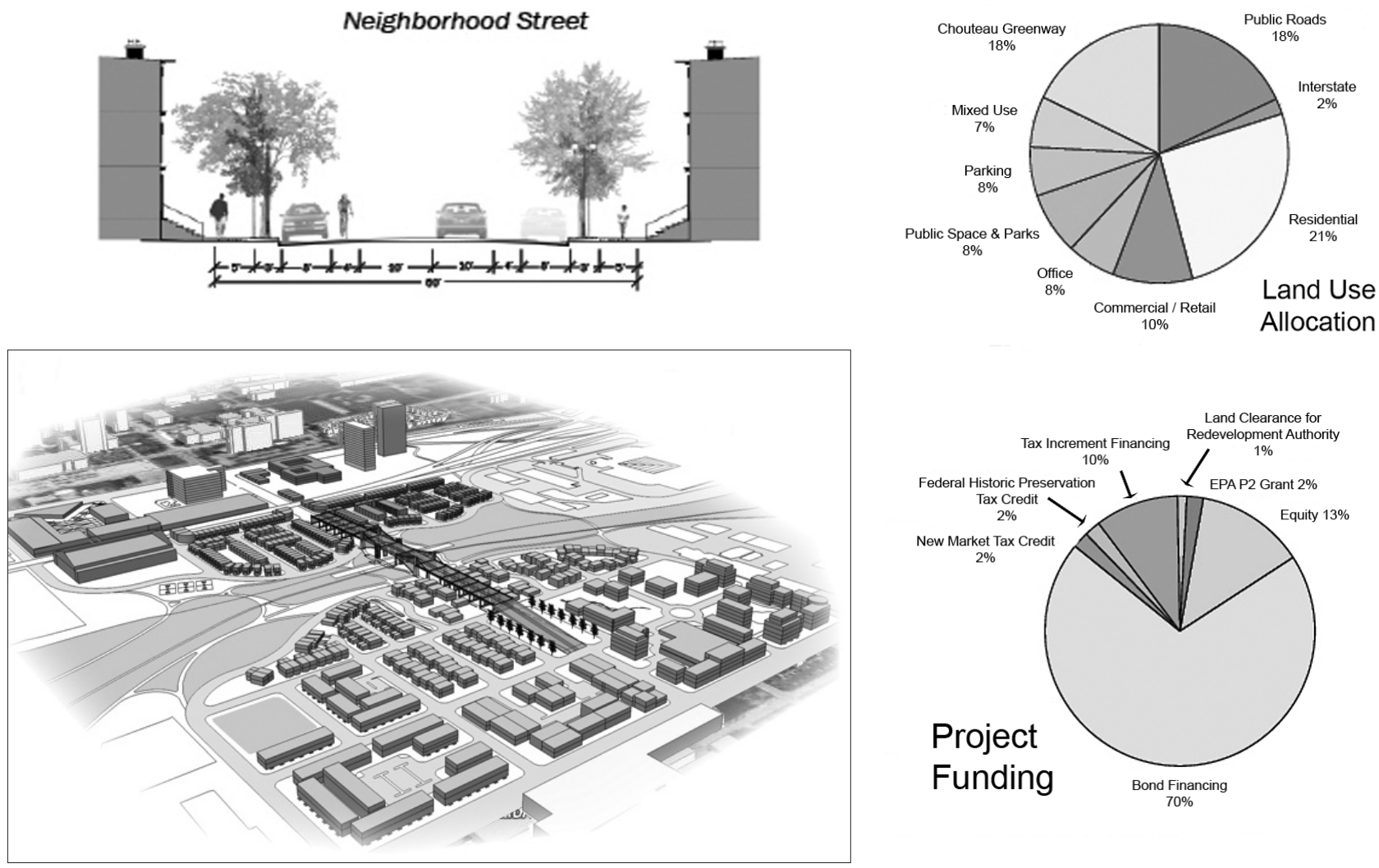